\title{
Prognostic factors and evaluation of a clinical score for predicting survival after resection of colorectal liver metastases
}

\author{
Ralf Konopke ${ }^{1}$, Stephan Kersting ${ }^{1}$, Marius Distler ${ }^{1}$, Jeannine Dietrich ${ }^{1}$, Jörg Gastmeier ${ }^{1}$, Axel Heller ${ }^{1}$, \\ Eberhard Kulisch ${ }^{2}$ and Hans-Detlev Saeger ${ }^{1}$ \\ 1 Department of General, Thoracic and Vascular Surgery, University of Technology, Dresden, Germany \\ 2 Institute of Medical Informatics and Biometrics, University of Technology, Dresden, Germany
}

\author{
Keywords \\ colorectal carcinoma - liver metastases - \\ prognostic factors - risk stratification - \\ survival
}

\section{Correspondence}

Ralf Konopke, MD, Department of General, Thoracic and Vascular Surgery, University of Technology, Fetscherstr. 74, 01307 Dresden, Germany

Tel: +493514584880

Fax: +49351449210301

e-mail: ralf.konopke@uniklinikum-dresden.de

\begin{abstract}
Background: Patient outcome after resection of colorectal liver metastases can be predicted by various prognostic factors. Aims: Development of a model for risk stratification based on analysis of prognostic factors. Methods: Data of 201 patients were collected prospectively and included in a single-centre trial. A total of 20 factors were analysed as to their influence on recurrence-free and overall survival. Independent prognostic factors were entered into a model of a clinical risk score. Results: Median recurrence-free survival reached 24 months for all patients; median overall survival was 50 months. Only a synchronous manifestation of primary colorectal carcinoma and liver metastases, the presence of four or more metastases and a carcino-embryonic antigen level of $200 \mathrm{ng} / \mathrm{ml}$ or more significantly influenced recurrence-free and overall survival in the multivariate analysis. The derived risk stratification grouped the patients according to the following criteria: low risk, zero prognostic factors $(n=112)$; intermediate risk, one factor $(n=74)$; high risk, two or more factors $(n=15)$. The median recurrence-free survival for low, intermediate and high risk were 30.0, 23.0 and 11.0 months, respectively; the median overall survival was 94.0, 40.0 and 33.0 months. Compared with the low-risk group, patients with intermediate risk demonstrated an increased hazard ratio (HR) of 1.57-fold for recurrence $(P=0.018)$ and 1.91-fold for mortality $(P=0.007)$. For the high-risk group, the HR rose significantly to 3.26 for recurrence $(P<0.0005)$ and to 3.10 for mortality $(P=0.001)$. Conclusions: The presented clinical score may allow for patients with colorectal liver metastases to be stratified appropriately and for optimization of their subsequent therapeutic management.
\end{abstract}

The management of colorectal liver metastases is a common and important clinical problem.

Twenty to $30 \%$ of patients with colorectal cancer develop synchronous or metachronous liver metastases. If untreated, these lesions have a poor prognosis, with a median survival ranking from 4 to 21 months and a 3-year survival below 3\% (1-3).

To date, after liver resection, patients can achieve a 5-year survival rate of up to $40 \%$, and resection still represents the treatment of choice. However, only $10-20 \%$ of patients fulfill selection criteria and are amenable to surgery (4-6).

Promising results in chemotherapy for primarily nonresectable liver metastases suggest an improvement in the outcome through the use of systemic chemotherapy with a neoadjuvant intent (7). Other treatment modalities, such as locoregional intra-arterial chemotherapy and local ablative therapy, have been accepted as palliative measures in patients with nonresectable disease $(8,9)$.

The basis for success of resection of liver metastases is the complete removal of all macroscopic liver lesions while preserving nontumorous liver, because incomplete resection is not associated with any clinical benefit and does not prolong survival (10).

Even if this criterion is carefully attended to, outcome of the patients depends on several prognostic factors. Identifying the dominant prognostic factors can help to categorize different patient risk groups and to stratify patients for entrance into different treatment protocols (11).

The present study aimed at identifying the value of potential prognostic factors depending on their influence of recurrencefree survival and overall survival. Therefore, a consecutive series of patients at our institution undergoing microscopically complete hepatectomy for colorectal liver metastases were reviewed. An additional objective was to develop a prognostic model that can effectively identify different risk groups based on clinicopathological parameters.

\section{Patients and methods}

Patients

From 1 October 1993 to 31 July 2006, 265 consecutive liver resections for colorectal liver metastases were performed at the Department of General, Thoracic and Vascular Surgery, University of Technology, Dresden, Germany.

Patients with primary cancer of the colon UICC III had undergone intravenous fluorouracil-based adjuvant chemotherapy; patients with primary rectal cancer UICC II and III had undergone adjuvant radiation with $50.4 \mathrm{~Gy}$ and fluorouracil-based chemotherapy. Recently (in the last 3 years), all patients with rectal cancer stages UICC II and III received 
neoadjuvant therapy (local radiation with $50.4 \mathrm{~Gy}$ and systemic fluorouracil-based chemotherapy).

Selective diagnostic workup for liver metastases included the measurement of carcino-embryonic antigen (CEA) level, abdominal ultrasonography and spiral computed tomography (CT) scan and colonoscopy. Only eight patients had percutaneous needle biopsies to confirm the presence of hepatic metastases.

All patients had to fulfill the following criteria to be considered a candidate for hepatic resection with curative intent: (i) hepatic metastases showed an adequate location and a corresponding well-vascularized hepatic remnant that remained after resection and (ii) the patients were medically fit for major hepatic resection.

An acceptable amount of liver parenchyma was guaranteed without pre-operative portal vein embolization to induce compensatory hypertrophy in all cases.

\section{Surgical management}

Surgical resections were performed by six experienced hepatobiliary surgeons. Intra-operatively, a complete exploration of the abdomen was performed to exclude extrahepatic metastases of colorectal cancer. In case of synchronous metastasis, resection of the primary tumour and the liver metastases were performed simultaneously in $25 \%$ of the patients according to the choice of the surgeon.

Before liver resection, the liver was completely mobilized, inspected and bimanually palpated. Surgeons performed intraoperative ultrasound using a flexible system (Sonoline Antara; Siemens Medical Solutions, Issaquah, WA, USA) and a 7.5$\mathrm{MHz}$ transducer to confirm the number and location of the metastases, as well as the relationship to the vascular and biliary landmarks.

Liver parenchyma dissection was performed with a cavipulse ultrasonic surgical aspirator (CUSA ${ }^{\mathbb{R}}$, Model 200T; Valley Lab., Boulder, CO, USA) or a water-jet-dissector in all cases. The portal inflow was isolated and temporarily occluded before parenchymal dissection, if necessary (Pringle-maneuver).

After liver resection, all operation specimens were macroscopically and microscopically examined and measured by a dedicated liver pathologist and documented on the pathology report.

\section{Follow-up}

In general, no adjuvant therapy followed after complete resection (R0) of the liver metastases.

Within the first 5 years after hepatic resection, patients were followed-up with six monthly clinical examinations, which included CEA level control and ultrasonography of the abdomen. A chest X-ray was performed yearly. Beginning 1 January 2003, sonographical follow-up routinely included contrastenhanced ultrasound.

An endoscopy (colonoscopy) was scheduled every 6 months for the first 2 years and yearly in the third through fifth years after resection of the primary tumour.

When new liver lesions were suspected sonographically, a spiral CT of the abdomen was performed. On discovery of lesions on chest X-rays or when elevated CEA levels were detected, a spiral CT of the chest was scheduled.

Survival data after the 5-year surveillance period were obtained by contacting the patients' oncologists.

Follow-up ended on 31 August 2007.

\section{Prognostic factors}

Age and gender as demographical data and type of liver resection, surgical margin and peri-/post-operative blood transfusion as surgical criteria were collected for each patient. Local liver findings included the number, the maximum diameter, the grading of the metastases and the localization within the liver and the number of infiltrated liver segments of the metastases. They also included the simultaneous manifestation of primary colorectal carcinoma and liver metastases and the CEA level. All these findings were grouped together as the 'liver-related oncological status'. The TNM classification and the grading of the primary tumour, the disease-free interval between diagnosis of the primary tumour and the liver metastases in case of metachronous metastasis and the accomplishment of neoadjuvant chemotherapy before liver resection were all classified as the 'extended oncological status'.

Systemic neoadjuvant chemotherapy was performed without randomization, aiming for response and improvement of longterm survival or for bridging between resections in metachronous resections of synchronous metastasis. No patient received regional chemotherapy by intra-arterial catheterization of the hepatic artery. The number and the localization of the liver metastases were determined intra-operatively. Satellite metastases within $3 \mathrm{~mm}$ from the main metastatic lesion were rated among the corresponding primary lesions and were not separately counted in the analysis. Satellite metastasis was detected in nine of 14 cases only in the histopathological evaluation of the specimen.

The grading and the maximum diameter of the metastases as well as the TNM classification and grading of the primary carcinoma were noted according to the histopathological report from the patients' files. In cases of multiple metastases, the maximum diameter was taken.

Blood transfusions were included in the analysis up to $48 \mathrm{~h}$ after the liver resections. Indication for transfusion was set according to haemoglobin levels and clinical signs of anaemia.

Endpoints of this study were recurrence (at any localization) and death. Correspondingly, intervals to this endpoint were defined as recurrence-free survival (interval between hepatic resection and recurrence) and overall survival (interval between liver resection and death). Patients not reaching any endpoint were censored at the time of the last follow-up for the Kaplan-Meier estimation.

Exclusion criteria for the analysis included recurrent liver metastases $(n=25)$, simultaneous extrahepatic tumour recurrence (recurrence of primary, extrahepatic metastases, $n=8$ ), simultaneous local ablative therapy $(n=8)$, intra-operative dissemination of tumour cells $(n=0)$, macroscopically or microscopically incomplete resection $(n=22)$ and hospital mortality $(n=1)$.

\section{Statistical analysis}

All data were collected prospectively at the Department of Surgery, Technical University of Dresden.

Recurrence-free survival and overall survival were estimated by the Kaplan-Meier method and are presented as percentages or as the median with a $95 \%$ confidence interval (CI).

The univariate influence of prognostic parameters on the recurrence-free survival and overall survival was assessed using Gehan's Wilcoxon test. A subgroup analysis of significant parameters followed using pairwise comparisons. 
Then, a multivariate analysis of the parameters was performed with regard to their independent influence on prognosis after adjustment for age, gender, type of liver resection, surgical margin and peri-/post-operative blood transfusion using the Cox proportional hazards analysis. Backwards elimination was applied, with inclusion of all parameters in the starting model. Variables were included if $P$-values were $<0.05$ und were removed if $P$-values were $>0.10$. The stability of the Cox proportional hazard model was assessed by a nonparametric bootstrap resampling technique. This was used to estimate the likelihood that each of the final model variables would have been selected in repeated samples.

Finally, patients were differentiated into risk groups according to the existence of significant factors in the multivariate analysis. The low-risk group comprised patients having zero factors, the intermediate-risk group had one factor and the high-risk group had $\geq 2$ factors. Differences of recurrence-free survival and overall survival were calculated using Gehan's Wilcoxon test again, and a risk analysis was performed (the univariate Cox proportional hazard model). To assess the influence of chemotherapy, a subanalysis of the neoadjuvantly treated patients was performed using a stratified Cox model, with differences assessed using Gehan's Wilcoxon test.

Results of the Cox proportional hazard models were displayed as hazard ratio (HR) with $95 \%$ CI.

A two-sided $P$-value of $<0.05$ was considered statistically significant. In multiple testing with pairwise comparisons, the $P$-value was adjusted using the Bonferroni-method.

All statistics were computed with SPSS 13.0 (SPSS Inc., Chicago, IL, USA).

\section{Results}

After exclusion according to the exclusion criteria, 201 patients (121 men, 80 women) with a median age of 65 years (range 39-88 years) were enrolled in this study.

Demographical data of the patients and criteria of the liver resection are shown in Table 1 , and showed no significant differences.
Surgeries performed were divided into 42 lobectomies, 18 trisegmentectomies, 27 bisegmentectomies, 90 segmentectomies or wedge resections and 24 combinations of resections plus contralateral wedge resections.

\section{Recurrence and survival}

After a median follow-up of 31 months (range 6-143 months) after hepatic resection, 126 patients $(62.7 \%)$ developed recurrence of the colorectal carcinoma. In 82 patients $(40.8 \%)$, recurrence was located exclusively within the liver. After hepatic recurrence, 15 patients underwent a second complete resection of metastases; two of these later underwent a third resection.

Primary manifestation of extrahepatic recurrence was a local recurrence of the primary tumour in nine cases, 18 cases of pulmonary metastases, four cases of brain metastases, two cases of bone metastases. Five times a recurrence was noted in the peritoneum and five times in the lymph nodes. Ten of these patients underwent curative resection of the recurrence.

Ninety-eight patients $(48.8 \%)$ expired within the followup period; 83 patient deaths $(84.7 \%)$ were due to tumour recurrence.

According to the Kaplan-Meier analysis, cumulative median recurrence-free survival was 24 months (95\%CI: 20.48-27.52), and the recurrence-free 1-, 3- and 5-year survival was 53, 30 and $28 \%$ respectively. Overall survivals were estimated at 50 months for the median (95\%CI: $31.28-68.72$ ) as well as 81,51 and $43 \%$ after 1,3 and 5 years respectively.

\section{Characterization of factors and univariate analysis}

\section{Factors for the 'liver-related oncological status'}

The details of the factors for 'liver-related oncological status' are presented in Table 2.

For the median, solitary liver metastases were resected (range: 1-8). The median diameter of the largest metastases was $34 \mathrm{~mm}$ (range: $4-141$ ), and the median CEA level at the time of diagnosis of the liver metastases was $4.4 \mathrm{ng} / \mathrm{ml}$ (range:

Table 1. Univariate analysis of demographical data and surgical criteria (Gehan's Wilcoxon test)

\begin{tabular}{|c|c|c|c|c|c|c|c|c|c|}
\hline & \multirow{2}{*}{$\begin{array}{l}\text { Number of } \\
\text { patients }\end{array}$} & \multirow{2}{*}{$\begin{array}{l}\text { Median } \\
\text { recurrence-free } \\
\text { survival (months) }\end{array}$} & \multicolumn{2}{|c|}{$95 \%$ confidence interval } & \multirow[b]{2}{*}{$P$-value } & \multirow{2}{*}{$\begin{array}{l}\text { Median } \\
\text { survival } \\
\text { (months) }\end{array}$} & \multicolumn{2}{|c|}{$95 \%$ confidence interval } & \multirow[b]{2}{*}{$P$-value } \\
\hline & & & Lower & Upper & & & Lower & Upper & \\
\hline Total & 201 & 24.0 & 20.48 & 27.52 & & 50.00 & 31.28 & 68.72 & \\
\hline \multicolumn{10}{|l|}{ Age (years) } \\
\hline$<60$ & 72 & 22.00 & 17.00 & 27.00 & \multirow[t]{2}{*}{0.092} & 45.00 & 22.15 & 67.85 & \multirow[t]{2}{*}{0.073} \\
\hline$>60$ & 129 & 27.00 & 22.41 & 31.59 & & 50.00 & 29.67 & 70.33 & \\
\hline \multicolumn{10}{|l|}{ Gender } \\
\hline Male & 121 & 25.00 & 19.63 & 30.37 & \multirow[t]{2}{*}{0.633} & 68.00 & 50.78 & 85.22 & \multirow[t]{2}{*}{0.378} \\
\hline Female & 80 & 24.00 & 19.22 & 28.78 & & 45.00 & 34.13 & 55.87 & \\
\hline \multicolumn{10}{|l|}{ Type of liver resection } \\
\hline Wegde & 67 & 18.00 & 7.63 & 28.37 & \multirow[t]{3}{*}{0.126} & 50.00 & 37.51 & 62.48 & \multirow[t]{3}{*}{0.280} \\
\hline Segmentectomies & 92 & 29.00 & 17.59 & 40.41 & & 52.00 & 29.64 & 74.36 & \\
\hline Lobectomy & 42 & 22.00 & 17.04 & 26.96 & & 42.00 & 30.12 & 54.63 & \\
\hline \multicolumn{10}{|l|}{ Surgical margin $(\mathrm{mm})$} \\
\hline$\geq 10$ & 93 & 24.00 & 20.25 & 27.75 & \multirow[t]{2}{*}{0.615} & 53.00 & 39.11 & 66.89 & \multirow[t]{2}{*}{0.523} \\
\hline $1-9$ & 108 & 24.00 & 15.84 & 32.16 & & 42.00 & 31.63 & 52.37 & \\
\hline \multicolumn{10}{|l|}{ Blood transfusion } \\
\hline Yes & 82 & 24.00 & 19.96 & 28.04 & \multirow[t]{2}{*}{0.844} & 40.00 & 33.56 & 46.44 & \multirow[t]{2}{*}{0.120} \\
\hline No & 118 & 25.00 & 19.51 & 30.50 & & 67.00 & 55.98 & 87.02 & \\
\hline
\end{tabular}


Table 2. Univariate analysis of prognostic factors of the 'liver-related oncological status' (Gehan's Wilcoxon test)

\begin{tabular}{|c|c|c|c|c|c|c|c|c|c|}
\hline & \multirow{2}{*}{$\begin{array}{l}\text { Number of } \\
\text { patients }\end{array}$} & \multirow{2}{*}{$\begin{array}{l}\text { Median } \\
\text { recurrence-free } \\
\text { survival } \\
\text { (months) }\end{array}$} & \multicolumn{2}{|c|}{$\begin{array}{l}95 \% \text { confidence } \\
\text { interval }\end{array}$} & \multirow[b]{2}{*}{$P$-value } & \multirow{2}{*}{$\begin{array}{l}\text { Median } \\
\text { survival } \\
\text { (months) }\end{array}$} & \multicolumn{2}{|c|}{$\begin{array}{l}95 \% \text { confidence } \\
\text { interval }\end{array}$} & \multirow[b]{2}{*}{$P$-value } \\
\hline & & & Lower & Upper & & & Lower & Upper & \\
\hline Total & 201 & 24.0 & 20.48 & 27.52 & & 50.00 & 31.28 & 68.72 & \\
\hline \multicolumn{10}{|c|}{ Time of diagnosis of the liver metastases } \\
\hline Synchronous & 70 & 23.00 & 17.37 & 28.63 & \multirow[t]{2}{*}{0.018} & 39.00 & 30.47 & 47.52 & \multirow[t]{2}{*}{0.030} \\
\hline Metachronous & 131 & 26.00 & 15.63 & 36.36 & & 53.00 & 35.06 & 70.94 & \\
\hline \multicolumn{10}{|c|}{ Number of liver metastases } \\
\hline 1 & 122 & 27.00 & 22.26 & 31.74 & \multirow[t]{4}{*}{0.003} & 55.00 & 41.56 & 69.85 & \multirow[t]{4}{*}{$<0.0005$} \\
\hline 2 & 44 & 26.00 & 14.46 & 37.54 & & 53.00 & 40.07 & 67.33 & \\
\hline 3 & 23 & 20.00 & 11.41 & 28.59 & & 39.00 & 26.44 & 51.56 & \\
\hline$\geq 4$ & 12 & 13.00 & 7.91 & 18.09 & & 23.00 & 17.34 & 28.66 & \\
\hline \multicolumn{10}{|c|}{ Maximum diameter of liver metastases (mm) } \\
\hline $0.1-19.9$ & 26 & 30.00 & 20.12 & 42.89 & \multirow[t]{4}{*}{0.663} & 67.00 & 55.36 & 78.64 & \multirow[t]{4}{*}{0.057} \\
\hline $20.0-49.9$ & 124 & 25.00 & 20.32 & 29.68 & & 47.00 & 36.36 & 57.64 & \\
\hline $50.0-79.9$ & 39 & 24.00 & 18.35 & 29.65 & & 41.00 & 30.09 & 51.91 & \\
\hline$\geq 80.0$ & 12 & 24.00 & 15.55 & 32.46 & & 31.00 & 23.78 & 38.22 & \\
\hline \multicolumn{10}{|l|}{ Grading of liver metastases } \\
\hline $\mathrm{GO} *$ & 6 & 21.00 & 9.19 & 34.80 & \multirow[t]{4}{*}{0.652} & 41.00 & 31.40 & 50.60 & \multirow[t]{4}{*}{0.953} \\
\hline G1 & 7 & 39.00 & 29.67 & 48.33 & & 52.00 & 30.94 & 73.08 & \\
\hline $\mathrm{G} 2$ & 158 & 25.00 & 20.13 & 29.86 & & 52.00 & 34.56 & 73.08 & \\
\hline G3 & 30 & 19.00 & 9.93 & 28.07 & & 41.00 & 35.96 & 46.04 & \\
\hline \multicolumn{10}{|c|}{ Localization of liver metastases } \\
\hline Left liver lobe & 38 & 29.00 & 24.64 & 33.36 & \multirow[t]{3}{*}{0.516} & 52.00 & 43.28 & 60.72 & \multirow[t]{3}{*}{0.810} \\
\hline Right liver lobe & 112 & 24.00 & 18.68 & 29.32 & & 47.00 & 36.13 & 57.87 & \\
\hline Both lobes & 51 & 24.00 & 17.12 & 30.88 & & 47.00 & 34.53 & 59.47 & \\
\hline Localization of liver metas & ases & & & & & & & & \\
\hline Peripherial & & & & & & & & & \\
\hline Segment $2 / 3$ & 16 & 37.00 & 30.12 & 44.88 & 0.241 & 52.00 & 31.62 & 74.92 & 0.809 \\
\hline Segment 6/7 & 43 & 35.00 & 16.77 & 53.23 & & 52.00 & 29.32 & 75.99 & \\
\hline Central & & & & & & & & & \\
\hline Segment 1/4b/5 & 29 & 17.00 & 9.36 & 25.13 & & 39.00 & 29.45 & 50.03 & \\
\hline Segment $4 a / 8$ & 26 & 32.00 & 25.34 & 39.65 & & 49.00 & 36.22 & 62.89 & \\
\hline Peripherial and central & 87 & 24.00 & 21.08 & 26.92 & & 43.00 & 28.82 & 57.18 & \\
\hline Number of infiltrated liver & segments & & & & & & & & \\
\hline 1 & 64 & 39.00 & 24.56 & 53.44 & 0.041 & 58.00 & 49.28 & 67.72 & 0.010 \\
\hline 2 & 78 & 23.00 & 17.58 & 28.42 & & 45.00 & 33.61 & 56.39 & \\
\hline 3 & 30 & 26.00 & 19.70 & 32.31 & & 47.00 & 37.63 & 56.36 & \\
\hline 4 & 24 & 23.00 & 19.49 & 26.51 & & 41.00 & 22.48 & 59.52 & \\
\hline$\geq 5$ & 5 & 11.00 & 8.85 & 13.15 & & 17.00 & 12.43 & 21.57 & \\
\hline CEA level (ng/ml) & & & & & & & & & \\
\hline $0.1-3.9 \dagger$ & 91 & 27.00 & 21.76 & 32.24 & 0.002 & 66.00 & 50.40 & 82.59 & 0.018 \\
\hline $4.0-99.0$ & 88 & 26.00 & 18.83 & 33.17 & & 52.00 & 41.42 & 62.58 & \\
\hline 100.0-199.9 & 13 & 13.00 & 9.72 & 16.28 & & 47.00 & 34.56 & 59.44 & \\
\hline$\geq 200$ & 9 & 13.00 & 7.16 & 18.84 & & 23.00 & 11.31 & 34.69 & \\
\hline
\end{tabular}

*Complete necrosis of the liver metastases after neoadjuvant chemotherapy.

$\dagger$ Normal level of CEA.

CEA, carcino-embryonic antigen.

0.3-8269.5). The number of infiltrated liver segments was distributed onto one-six segments (two in median).

Univariate analysis revealed that the following factors predicted the pattern of recurrence and influenced the overall survival: synchronous manifestation of primary colorectal carcinoma and liver metastases $(P=0.018$ and 0.030 ; supplementary Figure 1$)$, the number of liver metastases $(P=0.003$ and $<0.0005)$, the number of infiltrated liver segments $(P=0.041$ and 0.010$)$ and the CEA level $(P=0.002$ and 0.018$)$ (Table 2).

In the subanalysis of the number of metastases in the different groups, whatever their site, multiple liver metastases
( $\geq 4$ metastases) had a significant disadvantageous prognostic effect on the recurrence-free survival and overall survival in comparison with patients with one, two or three metastases within the liver (Fig. 1).

Comparing the number of infiltrated liver segments analysed in five groups, the infiltration of five or more liver segments showed the worst prognosis. When comparing recurrence-free survival, a significant difference as compared with the infiltration of only one segment was proven. In comparison with overall survival, a significant prognostic effect to all other analysed groups could be shown (Fig. 2). 


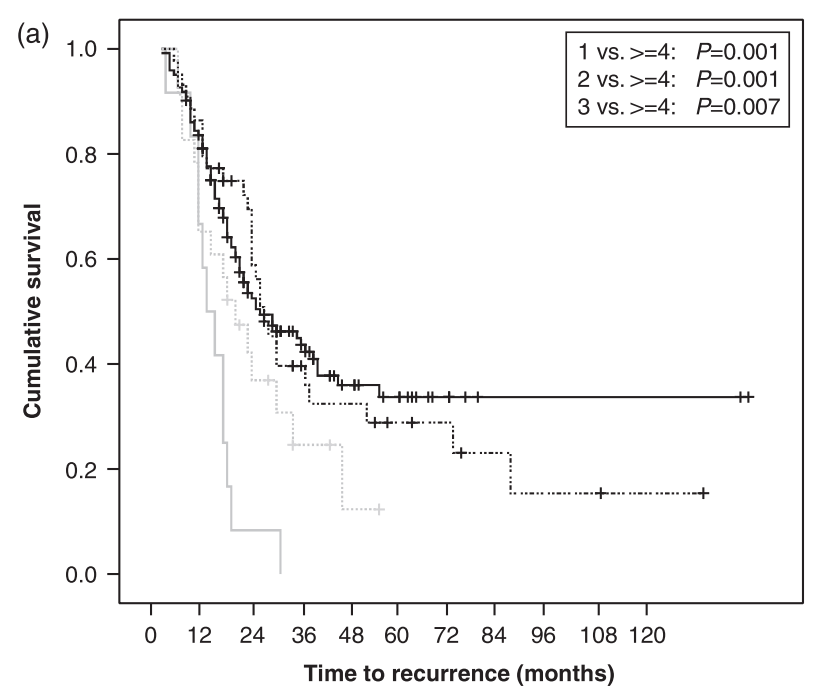

No. of the

liver metastases

\begin{tabular}{|r|l}
$\prod_{1}$ & 1 \\
\hdashline & 2 \\
\hdashline & 3
\end{tabular}

$>=4$

Patients at risk

$\begin{array}{lllllll}\text { Months postop. } & 0 & 12 & 24 & 36 & 48 & 60\end{array}$

No. of liver

metastases

$\begin{array}{rrrrrrr}1 & 122 & 100 & 52 & 35 & 19 & 14 \\ 2 & 44 & 38 & 26 & 12 & 9 & 6 \\ 3 & 23 & 15 & 8 & 3 & 1 & 0 \\ \geq 4 & 12 & 8 & 1 & 0 & 0 & 0\end{array}$

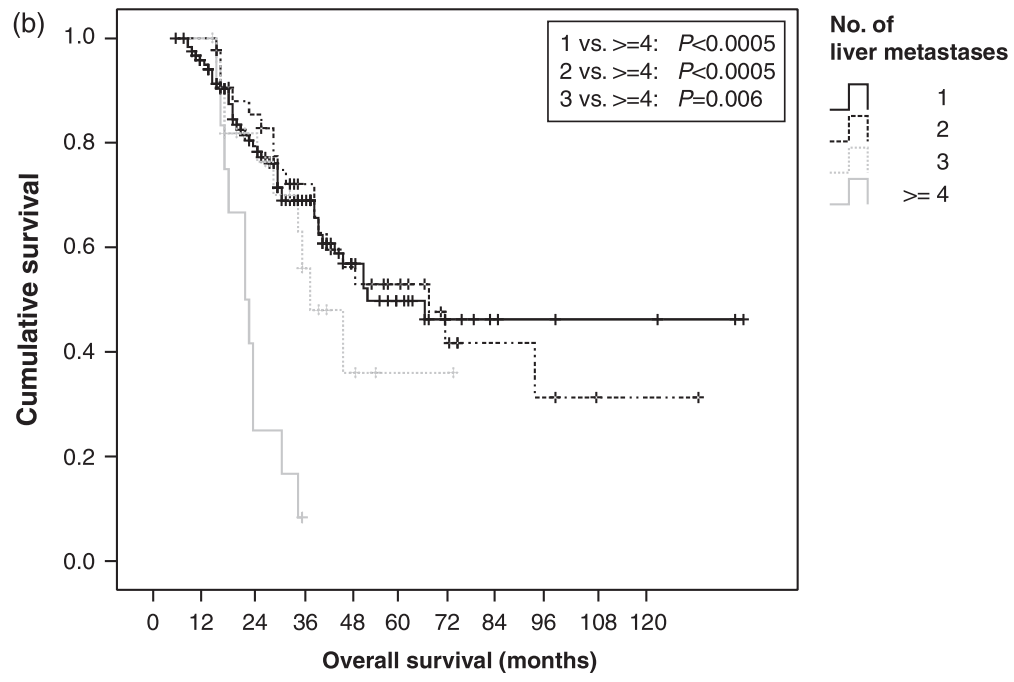

Patients at risk

$\begin{array}{lrrrrrrr}\begin{array}{l}\text { Months postop. } \\ \begin{array}{l}\text { No. of liver } \\ \text { metastases }\end{array}\end{array} & 0 & 12 & 24 & 36 & 48 & 60 \\ & 1 & 122 & 113 & 78 & 51 & 28 & 19 \\ & 2 & 44 & 44 & 34 & 24 & 17 & 13 \\ & 3 & 23 & 23 & 15 & 10 & 3 & 1 \\ & \geq 4 & 12 & 12 & 6 & 2 & 0 & 0\end{array}$

Fig. 1. (a) Recurrence-free survival rates of 201 patients according to the number of liver metastases (Gehan's Wilcoxon test; Bonferroniadjusted $P$-value $<0.008$ ). (b) Overall survival rates of 201 patients according to the number of the liver metastases (Gehan's Wilcoxon test; Bonferroni-adjusted $P$-value $<0.008)$ 


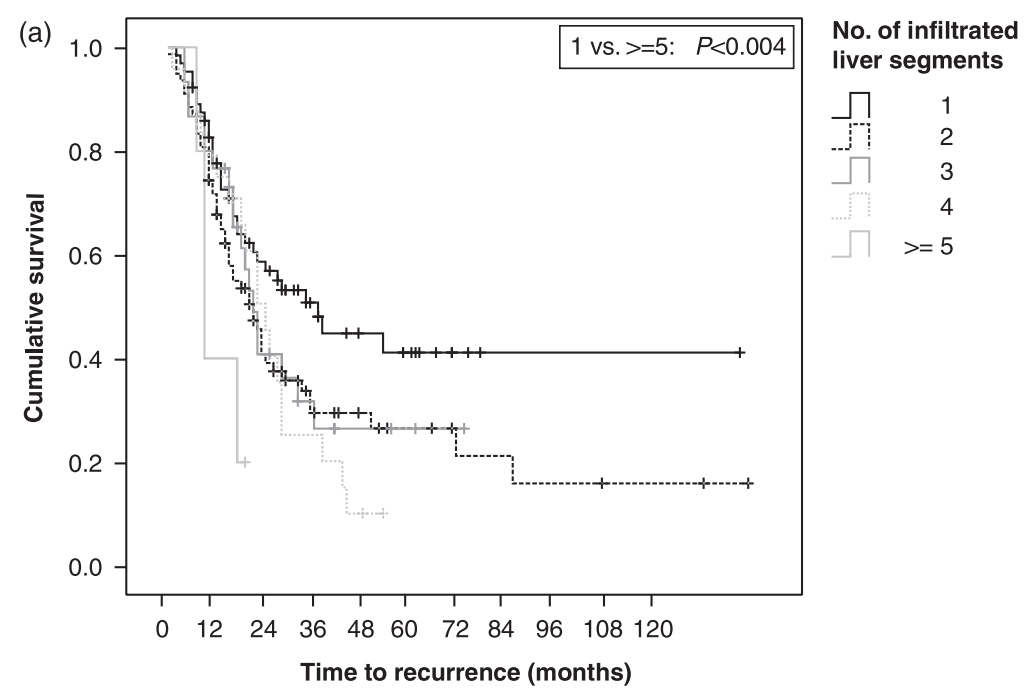

Patients at risk

Months postop.

$\begin{array}{llllll}0 & 12 & 24 & 36 & 48 & 60\end{array}$

No. of infiltrated

liver segments

$\begin{array}{rrrrrrr}1 & 64 & 53 & 34 & 22 & 13 & 11 \\ 2 & 78 & 63 & 29 & 17 & 11 & 7 \\ 3 & 30 & 24 & 12 & 6 & 3 & 2 \\ 4 & 24 & 19 & 12 & 5 & 2 & 0 \\ \geq 5 & 5 & 2 & 0 & 0 & 0 & 0\end{array}$

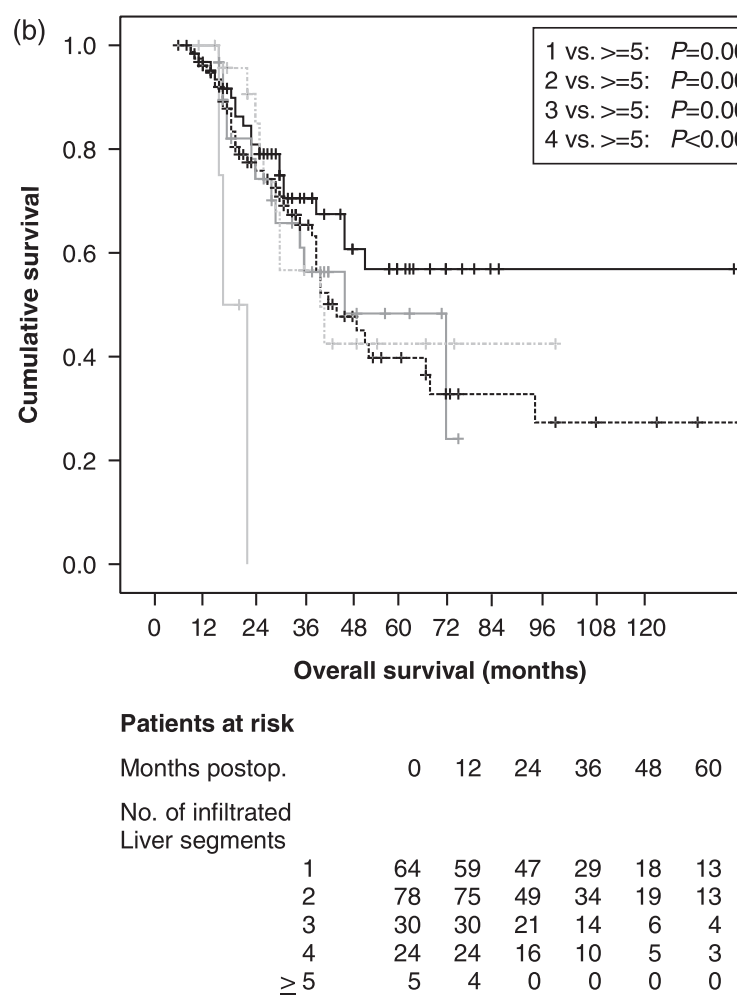

Fig. 2. (a) Recurrence-free survival rates of 201 patients according to the number of infiltrated liver segments (Gehan's Wilcoxon test; Bonferroni-adjusted $P$-value $<0.005$ ). (b) Overall survival rates of 201 patients according to the number of infiltrated liver segments (Gehan's Wilcoxon test; Bonferroni-adjusted $P$-value $<0.005)$. 
Finally, the cumulative recurrence-free survival and overall survival worsened significantly from a boundary CEA level of $200 \mathrm{ng} / \mathrm{ml}$ or more in comparison with the normal value $(0.1-3.9 \mathrm{ng} / \mathrm{ml})$ and a moderately increased CEA level (4.0-99.9 ng/ml) (Fig. 3).

The grading, the maximum diameter and the location of the metastases within the liver did not show any significant influence of the recurrence-free survival and overall survival (Table 2).

\section{Factors of the 'extended oncological status'}

Table 3 shows the results of the factors according to 'extended oncological status'.

In case of metachronous metastases, the median interval between resection of the primary tumour and the diagnosis of the liver metastases was 18 months (range 4-92 months).

Only a time of diagnosis of the liver metastases in an interval of $<12$ months after primary metastases had a significant prognostic effect for outcome of the patients in the univariate analysis $(P=0.044$ and 0.005 ; supplementary Figure 2$)$.

A prognostic influence of all other factors could not be shown (Table 3 ).

\section{Multivariate analysis}

At multivariate analysis, only factors of the 'liver-related oncological status' were independent predictors of poor prognosis (Table 4): four or more metastases influenced both the recurrence (HR: 3.60) and the mortality (HR: 4.62). The synchronous manifestation of the primary colorectal carcinoma was also an independent prognostic factor for recurrence (HR: 1.56) and survival (HR: 1.74). A CEA level of $200 \mathrm{ng} / \mathrm{ml}$ or more had an independent impact on mortality (HR: 2.73). No factors of the extended oncological status had an influence on the prognosis of the patients in the multivariate Cox regression.

To assess the stability of the final Cox proportional hazard model, a bootstrap resampling technique of 1250 bootstrap samples was performed with the parameters listed in Tables 2 and 3. The most frequently selected variables were those of the final model (Table 5).

\section{Risk-factor stratification}

The risk-factor stratification into three risk groups showed a significant influence on the occurrence of recurrence $(P=0.001)$ and on mortality $(P=0.020)$ (Table 6).

Compared with the group of low risk (no independent prognostic factor), patients with intermediate risk (one independent prognostic factor) demonstrated a 1.57 -fold increased HR for recurrence $(P=0.018)$ and a 1.91 -fold increased HR for mortality $(P=0.007)$. When looking at the high-risk group ( $\geq$ two independent prognostic factor), the HRs increased significantly for recurrence to $3.26(P<0.0005)$ and for mortality to $3.10(P=0.001)$ as compared with the low-risk group.

Correspondingly, significantly different survival outcomes between the groups according to their risk were proven (Fig. 4).

All patients of the high-risk groups developed a recurrence in a median of 11 months (range: 6-43 months) after resection of colorectal liver metastases. A complete resection of all recurrences was reached in four cases (recurrent liver metastases: $n=3$; lung metastases: $n=1$ ). However, a subsequent recur- rence of primary colorectal carcinoma occurred in all of these patients. Four patients of the high-risk group were alive and under palliative chemotherapy at the time of last follow-up. All other patients died of their malignant disease. None of the patients identified as high risk survived beyond 5 years.

The prognostic value of the risk stratification could be confirmed in a subgroup of patients having received neoadjuvant treatment (Table 7).

In a Cox analysis stratified by risk group to test for the effect of neoadjuvant therapy, the risk development of recurrence and tumour-related mortality increased significantly with increasing number of independent prognostic factors and led to a reduction of the median recurrence-free and overall survival. In detail, the median recurrence-free survival for the low-, intermediate- and high-risk group were 38, 23 and 18 months, respectively, and the median overall survival was 67,47 and 38 months. Significant differences between the survival rates of the three analysed risk groups after neoadjuvant chemotherapy could not be shown. However, patients in the 'high-risk' group having received neoadjuvant chemotherapy survived significantly longer compared with patients with primary resection of the liver metastases.

Thus, the estimated recurrence-free 5-year-survival after neoadjuvant chemotherapy was $14.3 \%$ compared with $0 \%$ after resection only $(P=0.016)$; the cumulative overall survival was found to be $21.4 \%$ vs. $0 \%(P=0.041)$.

\section{Discussion}

During the last 20 years, resection of colorectal liver metastases in selected patients with limited disease has been increasingly accepted by surgeons and medical oncologists. This is the result of the overwhelming evidence in favour of an associated survival benefit (12).

At the beginning, liver metastasis resection was restricted to small, solitary lesions within only one lobe of the liver. The improvement in pre-operative workup, anaesthesiological management and surgical technique, including vascular control of the hepatic pedicle with consequent reduction in the postoperative death to $<5 \%$, were the key points in expanding the indications for liver metastases resection in the recent years (13-16).

Because of the broadening indication of colorectal liver metastases resection, there is still debate over which groups of patients may benefit from surgery. Several prognostic factors have been already evaluated to define which of these affect longterm survival after colorectal liver metastases resection. Minagawa et al. (17) stressed that most variables are considered significant in $8-86 \%$ of the published articles. However, only the presence of lymph node metastases at the hepatic hilum has been consistently associated with poor prognosis (17). Given these differing data, we analysed our own patients whose data were continuously and prospectively collected over a period of 12 years and 8 months. The principal aim of this study was to define variables that can predict long-term outcome and to develop a model for risk stratification.

In the analysis, only patients with complete resection of the metastases were included because of the demonstration of unfavorable data for R1 resection of colorectal liver metastases in various studies (18-20). The completeness of tumour elimination from the liver was insured by the combination of intra-operative surgeon's macroscopic judgment (inspection and bimanual palpation) and ultrasonography of the liver. This 


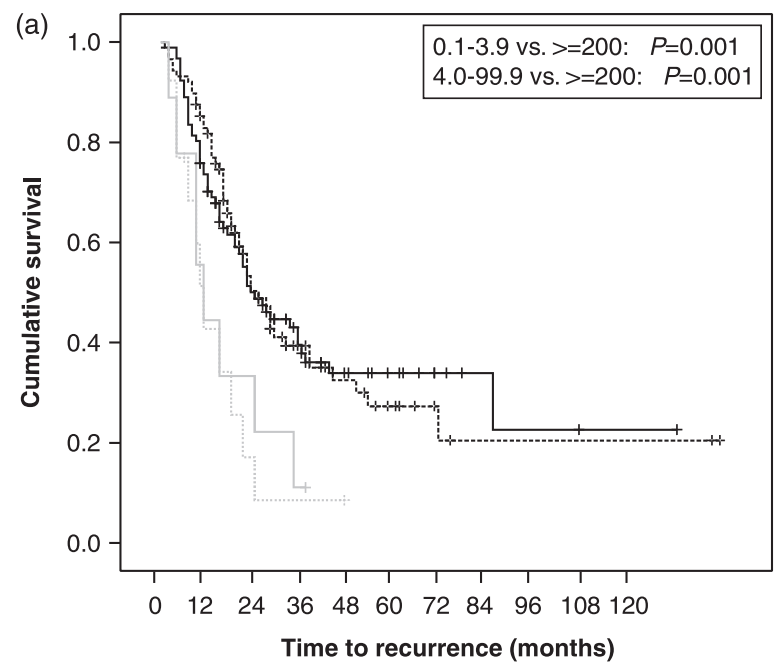

CEA level (ng/ml)

\ $0.1-3.9$

\begin{tabular}{ll}
$0.0-99.9$ \\
\hline
\end{tabular}

$100.0-199.9$

$\geq 200.0$

Patients at risk

$\begin{array}{lrrrrrr}\text { Months postop. } & 0 & 12 & 24 & 36 & 48 & 60 \\ \begin{array}{l}\text { CEA level } \\ (\mathrm{ng} / \mathrm{ml})\end{array} & & & & & & \\ 0.1-3.9 & 91 & 73 & 43 & 26 & 15 & 11 \\ 4.0-99.9 & 88 & 76 & 39 & 21 & 13 & 9 \\ 100.0-199.9 & 13 & 7 & 2 & 1 & 1 & 0 \\ >200.0 & 5 & 3 & 2 & 0 & 0 & \end{array}$

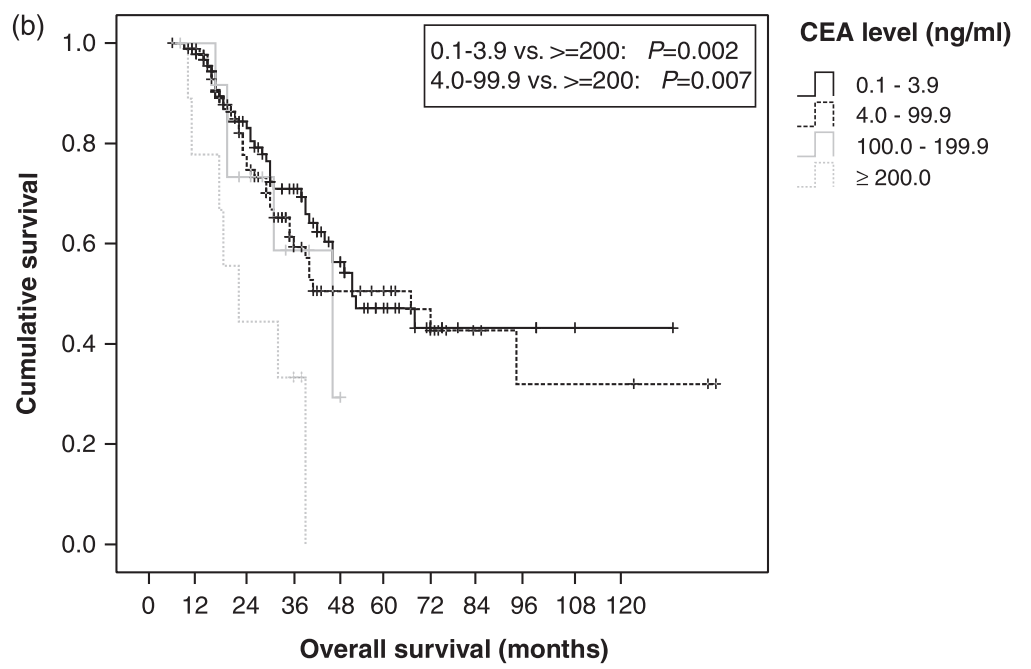

Patients at risk

$\begin{array}{lrrrrrr}\text { Months postop. } & 0 & 12 & 24 & 36 & 48 & 60 \\ \begin{array}{l}\text { CEA level } \\ \text { (ng/ml) }\end{array} & & & & & & \\ 0.1-3.9 & 91 & 89 & 66 & 47 & 28 & 16 \\ 4.0-99.9 & 88 & 84 & 56 & 34 & 19 & 17 \\ 100.0-199.9 & 13 & 12 & 7 & 3 & 1 & 0 \\ >200.0 & 9 & 7 & 4 & 3 & 0 & 0\end{array}$

Fig. 3. (a) Recurrence-free survival rates of 201 patients according to the carcino-embryonic antigen (CEA) level at the time of diagnosis of the liver metastases (Gehan's Wilcoxon test; Bonferroni-adjusted $P$-value $<0.008$ ). (b) Overall survival rates of 201 patients according to the CEA level at the time of diagnosis of the liver metastases (Gehan's Wilcoxon test; Bonferroni-adjusted $P$-value $<0.008$ ). 
Table 3. Univariate analysis of prognostic factors of 'extended oncological status' (Gehan's Wilcoxon test)

\begin{tabular}{|c|c|c|c|c|c|c|c|c|c|}
\hline & \multirow[b]{2}{*}{ Number of patients } & \multirow{2}{*}{$\begin{array}{l}\text { Median } \\
\text { recurrence-free } \\
\text { survival } \\
\text { (months) }\end{array}$} & \multicolumn{2}{|c|}{$\begin{array}{l}95 \% \text { confidence } \\
\text { interval }\end{array}$} & \multirow[b]{2}{*}{$P$-value } & \multirow{2}{*}{$\begin{array}{l}\text { Median } \\
\text { survival } \\
\text { (months) }\end{array}$} & \multicolumn{2}{|c|}{$\begin{array}{l}95 \% \text { confidence } \\
\text { interval }\end{array}$} & \multirow[b]{2}{*}{$P$-value } \\
\hline & & & Lower & Upper & & & Lower & Upper & \\
\hline Total & 201 & 24.0 & 20.48 & 27.52 & & 50.00 & 31.28 & 68.72 & \\
\hline \multicolumn{10}{|c|}{ Primary colorectal carcinoma } \\
\hline Rectum & 89 & 24.0 & 20.00 & 28.00 & \multirow[t]{2}{*}{0.389} & 47.0 & 37.36 & 66.64 & \multirow[t]{2}{*}{0.704} \\
\hline Colon & 112 & 26.0 & 18.05 & 38.95 & & 52.0 & 41.05 & 62.95 & \\
\hline \multicolumn{10}{|l|}{ T-stage } \\
\hline pT1 & 6 & 29.0 & 20.12 & 39.47 & \multirow[t]{4}{*}{0.213} & 70.0 & 50.12 & 90.33 & \multirow[t]{4}{*}{0.069} \\
\hline pT2 & 41 & 24.0 & 19.43 & 28.57 & & 47.0 & 37.28 & 56.72 & \\
\hline pT3 & 139 & 21.0 & 16.20 & 25.80 & & 41.0 & 32.55 & 49.45 & \\
\hline pT4 & 15 & 18.0 & 9.82 & 26.18 & & 29.0 & 22.24 & 35.76 & \\
\hline \multicolumn{10}{|l|}{ N-stage } \\
\hline pNO & 94 & 35.0 & 26.24 & 43.76 & \multirow[t]{3}{*}{0.351} & 69.0 & 49.21 & 89.55 & \multirow[t]{3}{*}{0.276} \\
\hline pN1 & 61 & 24.0 & 21.43 & 26.57 & & 67.0 & 52.26 & 81.74 & \\
\hline pN2 & 46 & 21.0 & 14.01 & 27.99 & & 40.0 & 29.37 & 50.63 & \\
\hline \multicolumn{10}{|l|}{ Grading } \\
\hline G1 & 7 & 39.0 & 29.67 & 48.33 & \multirow[t]{3}{*}{0.611} & 52.0 & 40.94 & 63.06 & \multirow[t]{3}{*}{0.717} \\
\hline $\mathrm{G} 2$ & 162 & 24.0 & 19.73 & 28.27 & & 52.0 & 34.09 & 69.92 & \\
\hline $\mathrm{G} 3$ & 32 & 19.0 & 9.61 & 28.40 & & 43.0 & 37.50 & 48.50 & \\
\hline \multicolumn{10}{|c|}{ Metachronous disease-free interval (months) } \\
\hline$<12$ & 102 & 22.0 & 17.93 & 26.07 & \multirow[t]{2}{*}{0.044} & 39.0 & 29.82 & 48.17 & \multirow[t]{2}{*}{0.005} \\
\hline$\geq 12$ & 99 & 30.0 & 20.92 & 39.08 & & 53.0 & 48.56 & 57.44 & \\
\hline$<24$ & 152 & 24.0 & 20.44 & 27.56 & \multirow[t]{2}{*}{0.098} & 47.0 & 36.51 & 57.49 & \multirow[t]{2}{*}{0.266} \\
\hline$\geq 24$ & 49 & 35.0 & 27.39 & 42.61 & & 72.0 & 54.52 & 89.48 & \\
\hline \multicolumn{10}{|c|}{ Neoadjuvant chemotherapy before liver resection } \\
\hline Yes & 43 & 23.0 & 18.55 & 27.45 & \multirow[t]{2}{*}{0.343} & 47.0 & 31.77 & 62.23 & \multirow[t]{2}{*}{0.867} \\
\hline No & 158 & 25.0 & 19.71 & 30.29 & & 52.0 & 41.09 & 62.91 & \\
\hline
\end{tabular}

Table 4. Multivariate analysis of prognostic factors (Cox proportional hazards analysis, backward elimination)

\begin{tabular}{|c|c|c|c|c|c|c|c|c|}
\hline & \multicolumn{4}{|l|}{ Recurrence } & \multicolumn{4}{|c|}{ Mortality } \\
\hline & \multirow[b]{2}{*}{ Hazard ratio } & \multicolumn{2}{|c|}{$\begin{array}{l}95 \% \text { confidence } \\
\text { interval }\end{array}$} & \multirow[b]{2}{*}{$P$-value } & \multirow{2}{*}{$\begin{array}{l}\text { Hazard } \\
\text { ratio }\end{array}$} & \multicolumn{2}{|c|}{$\begin{array}{l}95 \text { confidence } \\
\text { interval }\end{array}$} & \multirow[b]{2}{*}{$P$-value } \\
\hline & & Lower & Upper & & & Lower & Upper & \\
\hline Number of liver metastases $\geq 4$ & 3.60 & 2.86 & 5.18 & $<0.0005$ & 4.62 & 3.18 & 6.78 & $<0.0005$ \\
\hline CEA level $(\mathrm{ng} / \mathrm{ml}) \geq 200$ & & & & & 2.73 & 2.20 & 5.25 & 0.017 \\
\hline $\begin{array}{l}\text { Time of diagnosis of the liver } \\
\text { metastases: synchronous }\end{array}$ & 1.56 & 1.08 & 2.25 & 0.017 & 1.74 & 1.09 & 2.77 & 0.021 \\
\hline
\end{tabular}

CEA, carcino-embryonic antigen.

procedure seemed to be the most useful and applicable as a clinical approach and realized the highest detection rate for liver metastases (21). Thus, misjudgment as to the prognostic influence of the factors characterizing the local liver findings could be minimized. The R0 status of the resection specimens was guaranteed through routine pathohistological assessment of the smallest distance between the ink-marked resection edge and the tumour.

For a differentiated evaluation of the prognostic impact, all potential factors were allocated to either the 'liver-related oncological status' or to the 'extended oncological status'. The 'liver-related oncological status' included all factors that were collected at and around the time of liver metastasis resection. The 'extended oncological status' enhances prognostic value by adding anamnestic facts on the primary tumour, the tumour- free interval in metachronous disease and the procedure for downsizing of the metastases.

When we considered factors of 'extended oncological status', no single factor was sufficient for discriminating the potential for recurrence-free survival and overall survival in the multivariate analysis. In contrast, three of eight factors of 'liverrelated oncological status' showed an independent and significant influence on the outcome of disease. All of these factors describe the tumour load and the degree of aggressive tumour biology and characterize in detail a synchronous manifestation of primary colorectal carcinoma and liver metastases, a high number of liver metastases and an increased CEA level.

Patients who simultaneously detected colorectal liver metastases at the time of their colorectal carcinoma diagnosis have been regarded as a less biologically favorable group in terms of 
Table 5. Bootstrap investigation of the stability of the Cox proportional hazards model (1250 sample models)

\begin{tabular}{|c|c|c|}
\hline & \multicolumn{2}{|c|}{ Recurrence } \\
\hline & \multicolumn{2}{|c|}{ Frequency of selection for final model } \\
\hline & Number & $\%$ \\
\hline Number of liver metastases $\geq 4$ & 1012 & 81.0 \\
\hline Time of diagnosis of the liver metastases - synchronous & 980 & 78.4 \\
\hline CEA level $(\mathrm{ng} / \mathrm{ml}) \geq 200$ & 815 & 65.2 \\
\hline Number of infiltrated liver segments $\geq 5$ & 806 & 64.5 \\
\hline Metachronous disease-free interval (months) $\leq 12$ & 783 & 62.6 \\
\hline Primary colorectal carcinoma - N-stage & 779 & 62.3 \\
\hline Primary colorectal carcinoma - T-stage & 766 & 61.3 \\
\hline Localization of liver metastases - peripherial/central/ peripherial and central & 716 & 57.3 \\
\hline Maximum diameter of liver metastases $(\mathrm{mm})$ & 708 & 56.6 \\
\hline Grading of primary colorectal carcinoma & 673 & 53.8 \\
\hline Primary colorectal carcinoma - localization rectum & 670 & 53.6 \\
\hline Grading of liver metastases & 630 & 50.4 \\
\hline Localization of liver metastases - left/right/both liver lobes & 563 & 45.0 \\
\hline Metachronous disease-free interval (months) $\leq 24$ & 562 & 45.0 \\
\hline \multirow[t]{4}{*}{ Neoadjuvant chemotherapy before liver resection } & 549 & 43.9 \\
\hline & \multicolumn{2}{|l|}{ Mortality } \\
\hline & \multicolumn{2}{|c|}{ Frequency of selection for final model } \\
\hline & Number & $\%$ \\
\hline Number of liver metastases $\geq 4$ & 1087 & 87.0 \\
\hline CEA level $(\mathrm{ng} / \mathrm{ml})_{-} \geq 200$ & 1023 & 81.8 \\
\hline Time of diagnosis of the liver metastases - synchronous & 948 & 75.8 \\
\hline Metachronous disease-free interval (months) $\leq 12$ & 871 & 69.7 \\
\hline Number of infiltrated liver segments $\geq 5$ & 863 & 69.0 \\
\hline Maximum diameter of liver metastases (mm) & 860 & 68.8 \\
\hline Grading of primary colorectal carcinoma & 843 & 67.4 \\
\hline Primary colorectal carcinoma - T-stage & 820 & 65.6 \\
\hline Primary colorectal carcinoma - N-stage & 781 & 62.5 \\
\hline Neoadjuvant chemotherapy before liver resection & 772 & 61.8 \\
\hline Grading of liver metastases & 716 & 57.3 \\
\hline Metachronous disease-free interval (months) $\leq 24$ & 711 & 56.9 \\
\hline Localization of liver metastases - peripherial/central/peripherial and central & 681 & 54.5 \\
\hline Localization of liver metastases - left/right/both liver lobes & 617 & 49.4 \\
\hline Primary colorectal carcinoma - localization rectum & 608 & 48.6 \\
\hline
\end{tabular}

CEA, carcino-embryonic antigen.

Table 6. Risk stratification of 201 patients (univariate Cox proportional hazard analysis)

\begin{tabular}{|c|c|c|c|c|c|c|c|c|c|c|}
\hline & \multicolumn{5}{|c|}{ Recurrence } & \multicolumn{5}{|l|}{ Mortality } \\
\hline & \multirow{2}{*}{$\begin{array}{l}\text { Patients } \\
\text { (number) }\end{array}$} & \multirow{2}{*}{$\begin{array}{l}\text { Hazard } \\
\text { ratio }\end{array}$} & \multicolumn{2}{|c|}{$\begin{array}{l}95 \% \text { confidence } \\
\text { interval }\end{array}$} & \multirow[b]{2}{*}{$P$-value } & \multirow{2}{*}{$\begin{array}{l}\text { Patients } \\
\text { (number) }\end{array}$} & \multirow{2}{*}{$\begin{array}{l}\text { Hazard } \\
\text { ratio }\end{array}$} & \multicolumn{2}{|c|}{$\begin{array}{l}95 \% \text { confidence } \\
\text { interval }\end{array}$} & \multirow[b]{2}{*}{$P$-value } \\
\hline & & & Lower & Upper & & & & Lower & Upper & \\
\hline Low risk & 112 & 1.00 & & & $0.001^{*}$ & 108 & 1.00 & & & $0.020^{*}$ \\
\hline Intermediate risk & 74 & 1.57 & 1.08 & 2.28 & $0.018^{* *}$ & 75 & 1.91 & 1.19 & 3.05 & $0.007^{* *}$ \\
\hline High risk & 15 & 3.26 & 1.81 & 5.88 & $<0.0005^{* * *}$ & 18 & 3.10 & 1.58 & 6.07 & $0.001^{* * *}$ \\
\hline
\end{tabular}

*P-value for baseline hazard.

** Comparison low risk vs. intermediate risk.

${ }^{* * *}$ Comparison low risk vs. high risk.

survival because tumour cells have already spread to a distant organ even before the treatment of the primary cancer (22). This resulted in an impaired prognosis, as shown in various studies $(23,24)$. It was corroborated by the multivariate analysis in our study, with a reduction in the recurrence-free and overall survival.

The optimal timing and indication for surgical resection of synchronous liver metastases is still controversial. It has been 
(a)

\begin{tabular}{|l|c|c|cc|c|c|c|}
\hline risk group & No & $\begin{array}{c}\text { Median } \\
\text { recurrence } \\
\text { free survival } \\
\text { (months) }\end{array}$ & $\begin{array}{c}\text { क } \\
\text { Confidence } \\
\text { Interval }\end{array}$ & $\begin{array}{c}\text { 1-year } \\
\text { Recurrence } \\
\text { fower }\end{array}$ & $\begin{array}{c}\text { Upper } \\
\text { free survival } \\
(\%)\end{array}$ & $\begin{array}{c}\text { U-year } \\
\text { Recurrence } \\
\text { free survival } \\
(\%)\end{array}$ & $\begin{array}{c}\text { 5-year } \\
\text { Recurrence } \\
\text { free survival } \\
(\%)\end{array}$ \\
\hline overall & 201 & 24.0 & 20.48 & 27.52 & 53 & 30 & 28 \\
\hline low risk & 112 & 30.0 & 23.10 & 36.90 & 89 & 50 & 40 \\
\hline intermediate risk & 74 & 23.0 & 19.23 & 26.76 & 83 & 30 & 18 \\
\hline high risk & 15 & 11.0 & 4.69 & 17.31 & 46 & 6 & 0 \\
\hline
\end{tabular}

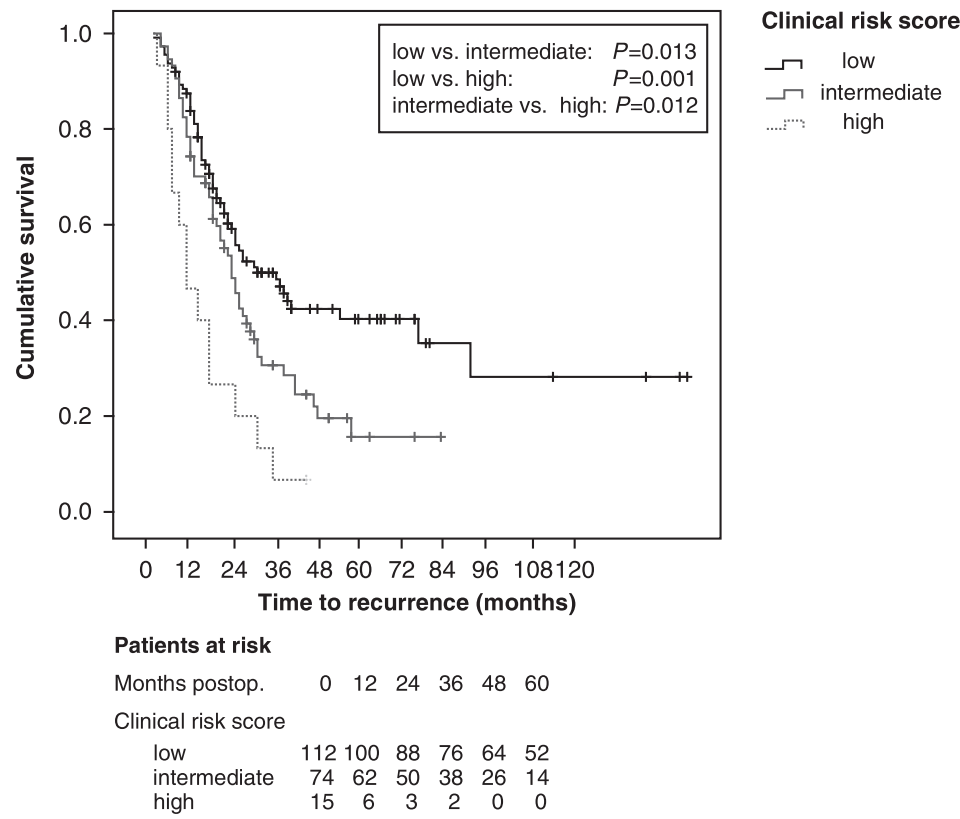

(b)

\begin{tabular}{|c|c|c|c|c|c|c|c|}
\hline \multirow[t]{2}{*}{ risk group } & \multirow[t]{2}{*}{ No } & \multirow{2}{*}{$\begin{array}{l}\text { Median } \\
\text { overall } \\
\text { survival } \\
\text { (months) }\end{array}$} & \multicolumn{2}{|c|}{$\begin{array}{c}95 \% \\
\text { Confidence } \\
\text { Interval }\end{array}$} & \multirow{2}{*}{$\begin{array}{c}\text { 1-year } \\
\text { Overall } \\
\text { survival } \\
(\%)\end{array}$} & \multirow{2}{*}{$\begin{array}{c}\text { 3-year } \\
\text { Overall } \\
\text { survival } \\
(\%)\end{array}$} & \multirow{2}{*}{$\begin{array}{c}5 \text {-year } \\
\text { Overall } \\
\text { survival } \\
(\%)\end{array}$} \\
\hline & & & Lower & Upper & & & \\
\hline overall & 201 & 50.0 & 31.28 & 68.72 & 81 & 51 & 43 \\
\hline low risk & 108 & 94.0 & 59.00 & 128.99 & 95 & 79 & 57 \\
\hline intermediate risk & 75 & 40.0 & 30.75 & 49.25 & 90 & 63 & 38 \\
\hline high risk & 18 & 33.0 & 23.21 & 42.79 & 35 & 26 & 0 \\
\hline
\end{tabular}

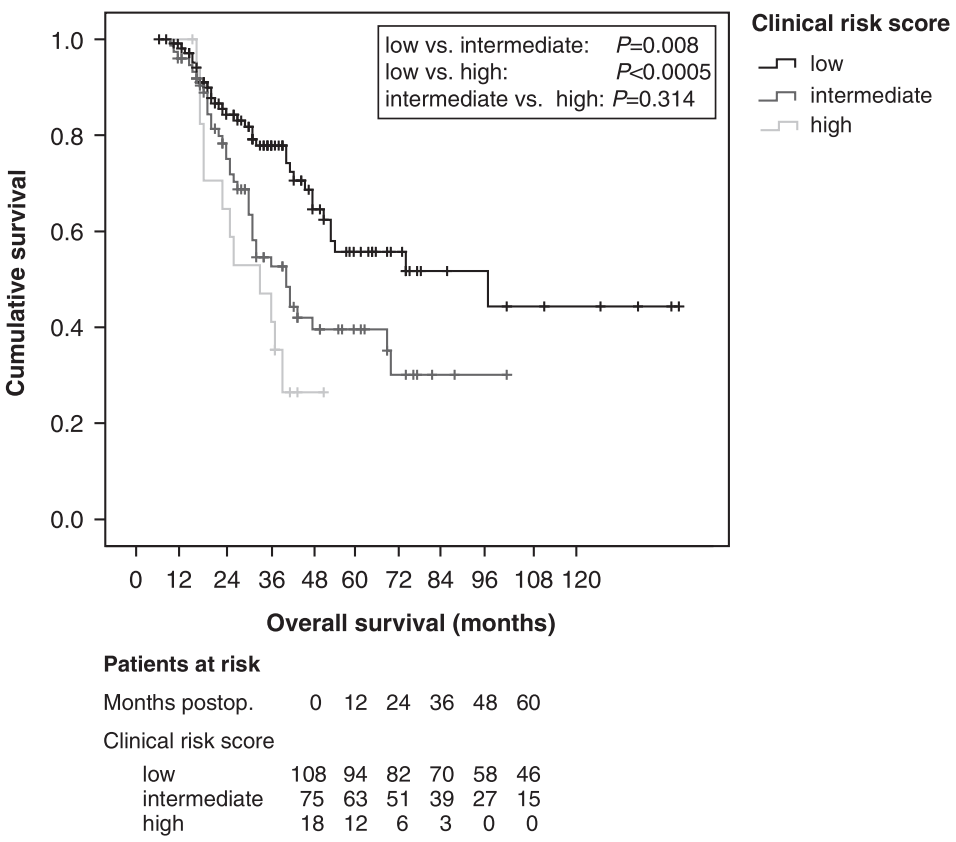

Fig. 4. (a) Recurrence-free survival as related to the clinical risk score. (b) Overall survival as related to the clinical risk score. 
Table 7. Risk stratification of 43 patients after neoadjuvant chemotherapy (univariate Cox proportional hazard analysis)

\begin{tabular}{|c|c|c|c|c|c|c|c|c|c|c|}
\hline & \multicolumn{5}{|c|}{ Recurrence } & \multicolumn{5}{|l|}{ Mortality } \\
\hline & \multirow{2}{*}{$\begin{array}{l}\text { Patients } \\
\text { (number) }\end{array}$} & \multirow{2}{*}{$\begin{array}{l}\text { Hazard } \\
\text { ratio }\end{array}$} & \multicolumn{2}{|c|}{$\begin{array}{l}95 \% \text { confidence } \\
\text { interval }\end{array}$} & \multirow[b]{2}{*}{$P$-value } & \multirow{2}{*}{$\begin{array}{l}\text { Patients } \\
\text { (number) }\end{array}$} & \multirow{2}{*}{$\begin{array}{l}\text { Hazard } \\
\text { ratio }\end{array}$} & \multicolumn{2}{|c|}{$\begin{array}{l}95 \% \text { confidence } \\
\text { interval }\end{array}$} & \multirow[b]{2}{*}{$P$-value } \\
\hline & & & Lower & Upper & & & & Lower & Upper & \\
\hline Low risk & 9 & 1.00 & & & $0.005^{*}$ & 8 & 1.00 & & & $0.043^{*}$ \\
\hline Intermediate risk & 27 & 1.90 & 0.648 & 3.559 & $0.015^{* *}$ & 27 & 1.40 & 0.402 & 3.054 & $0.023^{* *}$ \\
\hline High risk & 7 & 2.63 & 0.602 & 4.575 & $0.001^{* * *}$ & 8 & 2.06 & 0.459 & 6.211 & $0.009^{* * *}$ \\
\hline
\end{tabular}

shown that synchronous resection of colorectal liver metastases is associated with a low peri-operative morbidity rate $(25,26)$. On the other hand, many surgeons advocate the resection of the colorectal primary tumour first and then to wait about 3 months to monitor the disease progression. If the hepatic involvement remains stable, these patients are then considered for subsequent liver resection (27-29). This 'interval' approach might allow occult metastases to become detectable, and patients who develop inoperable metastases during this 'time of re-evaluation' may avoid another major surgery. In summary, this staged approach allows for selection of a favourable group for liver resection (30).

Another therapeutic approach included the enrollment of patients into multimodal treatment procedures with chemotherapy and resection. However, it is unclear whether to prefer simultaneous resection followed by adjuvant chemotherapy or neoadjuvant chemotherapy followed by liver resection $(31,32)$. In the present trial, no adjuvant chemotherapy followed after complete resection of simultaneous colorectal liver metastases. Neoadjuvant chemotherapy was performed in $81.4 \%$ of synchronous liver metastases before metachronous resection ( $n=35$ of 43 cases) and did not lead to an improvement in survival. Ultimately, the decision about the therapeutic procedure in the case of simultaneous colorectal liver metastases remains subjective, depending on the expertise and on the aggressiveness of the surgeon (32).

The number of colorectal liver metastases, when they are resectable, is a predictor of both poorer recurrence-free and overall survival $(28,33,34)$. The predictive value of the number of lesions for survival is unclear. The discussion has focused on the cut-off number of four metastases. For some authors, this number represents the boundary between patients who are capable of achieving an acceptable outcome and those who are not $(5,33,35)$. Among others, the results of Shimada et al. (36), published in 2004, with a cumulative overall 5-year survival rate of $46.7 \%$ after resection of five or more colorectal liver metastases, speak for an operative procedure. On the other hand, according to the results of systemic chemotherapy with prolonged survival beyond 2 years in a palliative setting, a more conservative approach would appear to be appropriate (7). In the present trial, four or more liver metastases proved to be independent predictors, with highest HRs for recurrence development (HR: 3.60) and mortality (HR: 4.62) in the multivariate analysis. In addition, four or more liver metastases were the most frequently selected variable in the bootstrapping analysis of 1250 bootstrap samples.

A recently published series described a limitation of the prognosis for patients with eight or more liver metastases.
These patients were more likely to develop hepatic recurrence within 6 months as well as extrahepatic recurrences and unresectable disease $(34,37)$. Until a definitive consent is reached, we believe that patients with multiple colorectal liver metastases, irrespective of their size and location, should always be evaluated by an experienced hepatobiliary surgeon. Hepatic resection should be performed in such a way that a balance is maintained between radical removal of the tumours, minimal blood loss and maximum residual hepatic mass (10).

The CEA levels characterize the malignancy of the colorectal carcinoma as well as the metastases and the tumour load. An elevated CEA level at the time of diagnosis of the metastases is a poor prognostic sign and correlates with reduced survival even if a complete resection of the liver metastases can be realized (38). Specifically, pre-operative CEA levels of $200 \mathrm{ng} / \mathrm{ml}$ or more have been evaluated as a characteristic of aggressive tumour biology $(20,39)$. Accordingly, this study confirmed this boundary as an independent parameter for reduced overall survival.

Prognostic scoring systems have been described in several cancer types and are being increasingly used in clinics to define different risk groups for patients with different cancers $(32,40$, 41). In the present trial, variables that reached significance for recurrence-free and overall survival on multivariate analysis were entered into a clinical risk score. Using this risk stratification, we were able to refine our prognostic estimation such that if one had no independent prognostic risk factors, the estimated 5 -year recurrence-free survival associated with complete surgical resection would be $40 \%$ and the estimated 5-year overall survival would be $57 \%$. Accordingly, the low-risk group is predicted to have a significantly better estimated survival without recurrence and overall survival when compared with the intermediate- and the high-risk groups. None of the patients with two or more independent prognostic factors (high-risk group) would be alive beyond 5 years from resection.

Application of this refined prognostic estimation may be used to identify patients who might benefit from differentiated therapeutic procedures, especially in light of more effective chemotherapy regimens, which have produced a large impact on the survival of the patient with hepatic colorectal metastases (12). Analogously, in the present study, patients of the 'highrisk' group having received neoadjuvant chemotherapy show significantly better survival than after resection only, as proven in a comparison between the stratifications of neoadjuvantly treated and primarily resected patients.

However, for planning of surgery, potential side effects of the chemotherapy have to be taken into account. 
Thus, especially in patients with known steatosis and in patients at known risk for steatosis (e.g. with a high body mass index, diabetes mellitus and predisposing metabolic syndrome) there is a markedly elevated risk for the development of a chemotherapy-associated steatohepatitis syndrome and associated complications (42). These lead to a reduction of the hepatic reserve, consecutively increasing the rate of postoperative liver failure, especially after 'major resections' (43, 44). In this situation, it can be useful to decide which type of hepatectomy should be performed. When the choice is possible between several wedge resections or a major liver resection removing at once all the deposits, wedge resections should be preferred to ensure maximum remaining liver parenchyma (43). Additionally, pre-operative portal vein embolization should be considered, which has been recommended to induce hypertrophy of the liver uninvolved with tumour, when the estimated functional liver remant is $<30-40 \%$ (45). This can eventually lead to a change in the management, such as substitution of local ablative techniques for resection to avoid post-operative liver insufficiency (46).

The implementation of the presented score system to preoperatively stratify patients according to their prognosis has still to be evaluated. The transfer of the CEA level and the synchronous manifestation of primary colorectal carcinoma and liver metastases into the model seem unproblematic. However, the pre-operative definition of the exact number of metastases could prove difficult because pre-operative diagnostic methods and the PET reach only sensitivities of $<90 \%$ in comparison with intra-operatively obtained findings in the liver $(47,48)$.

\section{Conclusion}

This study represents a single-centre analysis of prognostic factors for 201 patients with complete resections of colorectal liver metastases. All variables that influenced prognosis in the multivariate analysis (CEA level $\geq 200 \mathrm{ng} / \mathrm{ml}$, number of liver metastases $\geq 4$ and time of diagnosis of the liver metastases synchronous to primary colorectal carcinoma) were evaluated at the time of liver metastases resection. Based on these factors, a clinical scoring system was developed to allow patients to be appropriately stratified to optimize their subsequent management. In particular, patients of the high-risk group are candidates for a multimodal therapy concept as their cumulative survival probability after resection alone is limited to $<5$ years and may profit from neoadjuvant chemotherapy before resection.

\section{References}

1. Foster JH. Survival after liver resection for secondary tumors. Am J Surg 1978; 135: 389-94.

2. Levine AW, Donegan WL, Irwin M. Adenocarcinoma of the colon with hepatic metastases. Fifteen-year survival. JAMA 1982; 247: 2809-10.

3. Stangl R, Altendorf-Hofmann A, Charnley RM, Scheele J. Factors influencing the natural history of colorectal liver metastases. Lancet 1994; 343: 1405-10.

4. Nakamura S, Suzuki S, Baba S. Resection of liver metastases of colorectal carcinoma. World J Surg 1997; 21: 741-7.

5. Nordlinger B, Guiguet M, Vaillant JC, et al. Surgical resection of colorectal carcinoma metastases to the liver. A prognostic scoring system to improve case selection, based on 1568 patients. Association Francaise de Chirurgie. Cancer 1996; 77: 1254-62.

6. Scheele J, Altendorf-Hofmann A, Grube T, Hohenberger W, Stangl $\mathrm{R}$, Schmidt K. Resection of colorectal liver metastases. What prognostic factors determine patient selection? Chirurg 2001; 72: 547-60.

7. Folprecht G, Grothey A, Alberts S, Raab HR, Kohne CH. Neoadjuvant treatment of unresectable colorectal liver metastases: correlation between tumour response and resection rates. Ann Oncol 2005; 16: 1311-9.

8. Geoghegan JG, Scheele J. Treatment of colorectal liver metastases. Br J Surg 1999; 86: 158-69.

9. Rosen SA, Buell JF, Yoshida A, et al. Initial presentation with stage IV colorectal cancer: how aggressive should we be? Arch Surg 2000; 135: 530-4; discussion 34-5.

10. Malafosse R, Penna C, Sa Cunha A, Nordlinger B. Surgical management of hepatic metastases from colorectal malignancies. Ann Oncol 2001; 12: 887-94.

11. Lahr CJ, Soong SJ, Cloud G, Smith JW, Urist MM, Balch CM. A multifactorial analysis of prognostic factors in patients with liver metastases from colorectal carcinoma. J Clin Oncol 1983; 1: 720-6.

12. Tomlinson JS, Jarnagin WR, Dematteo RP, et al. Actual 10-year survival after resection of colorectal liver metastases defines cure. J Clin Oncol 2007; 25: 4575-80.

13. Cummings LC, Payes JD, Cooper GS. Survival after hepatic resection in metastatic colorectal cancer: a population-based study. Cancer 2007; 109: 718-26.

14. Ercolani G, Grazi GL, Ravaioli M, et al. Liver resection for multiple colorectal metastases: influence of parenchymal involvement and total tumor volume, vs number or location, on long-term survival. Arch Surg 2002; 137: 1187-92.

15. Grazi GL, Mazziotti A, Jovine E, et al. Total vascular exclusion of the liver during hepatic surgery. Selective use, extensive use, or abuse? Arch Surg 1997; 132: 1104-9.

16. Mann CD, Neal CP, Pattenden CJ, et al. Major resection of hepatic colorectal liver metastases in elderly patients - an aggressive approach is justified. Eur J Surg Oncol 2007; 34: 428-32.

17. Minagawa M, Makuuchi M, Torzilli G, et al. Extension of the frontiers of surgical indications in the treatment of liver metastases from colorectal cancer: long-term results. Ann Surg 2000; 231: 487-99.

18. Elias D, Cavalcanti A, Sabourin JC, Pignon JP, Ducreux M, Lasser P. Results of 136 curative hepatectomies with a safety margin of less than $10 \mathrm{~mm}$ for colorectal metastases. J Surg Oncol 1998; 69: 88-93.

19. Hamady ZZ, Cameron IC, Wyatt J, Prasad RK, Toogood GJ, Lodge JP. Resection margin in patients undergoing hepatectomy for colorectal liver metastasis: a critical appraisal of the $1 \mathrm{~cm}$ rule. Eur J Surg Oncol 2006; 32: 557-63.

20. Pawlik TM, Scoggins CR, Zorzi D, et al. Effect of surgical margin status on survival and site of recurrence after hepatic resection for colorectal metastases. Ann Surg 2005; 241: 715-22; discussion 22-4.

21. Hoelscher TJ, Mccall WV, Powell J, Marsh GR, Erwin CW. Two methods of scoring sleep with the Oxford Medilog 9000: comparison to conventional paper scoring. Sleep 1989; 12: 133-9.

22. Scheele J, Stang R, Altendorf-Hofmann A, Paul M. Resection of colorectal liver metastases. World J Surg 1995; 19: 59-71.

23. Hao CY, Ji JF. Surgical treatment of liver metastases of colorectal cancer: strategies and controversies in 2006. Eur J Surg Oncol 2006; 32: 473-83.

24. Scheele J, Altendorf-Hofmann A. Resection of colorectal liver metastases. Langenbecks Arch Surg 1999; 384: 313-27.

25. De Santibanes E, Lassalle FB, Mccormack L, et al. Simultaneous colorectal and hepatic resections for colorectal cancer: postoperative and longterm outcomes. J Am Coll Surg 2002; 195: 196-202. 
26. Martin R, Paty P, Fong Y, et al. Simultaneous liver and colorectal resections are safe for synchronous colorectal liver metastasis. J Am Coll Surg 2003; 197: 233-41; discussion 41-2.

27. Bismuth H, Castaing D, Traynor O. Surgery for synchronous hepatic metastases of colorectal cancer. Scand J Gastroenterol 1988; 149(Suppl.): 144-9.

28. Cady B, Jenkins RL, Steele GD Jr., et al. Surgical margin in hepatic resection for colorectal metastasis: a critical and improvable determinant of outcome. Ann Surg 1998; 227: 566-71.

29. Lambert LA, Colacchio TA, Barth RJ Jr. Interval hepatic resection of colorectal metastases improves patient selection. Arch Surg 2000; 135: 473-9; discussion 79-80.

30. Yan TD, Chu F, Black D, King DW, Morris DL. Synchronous resection of colorectal primary cancer and liver metastases. World J Surg 2007; 31: 1496-501.

31. Capussotti L, Vigano L, Ferrero A, Lo Tesoriere R, Ribero D, Polastri R. Timing of resection of liver metastases synchronous to colorectal tumor: proposal of prognosis-based decisional model. Ann Surg Oncol 2007; 14: 1143-50.

32. Lee WS, Kim MJ, Yun SH, et al. Risk factor stratification after simultaneous liver and colorectal resection for synchronous colorectal metastasis. Langenbecks Arch Surg 2008; 393: 13-9.

33. Gayowski TJ, Iwatsuki S, Madariaga JR, et al. Experience in hepatic resection for metastatic colorectal cancer: analysis of clinical and pathologic risk factors. Surgery 1994; 116: 703-10; discussion 10-1.

34. Malik HZ, Hamady ZZ, Adair R, et al. Prognostic influence of multiple hepatic metastases from colorectal cancer. Eur J Surg Oncol 2007; 33: 468-73.

35. Imamura $\mathrm{H}$, Kawasaki S. Treatment strategy for multiple hepatic metastases of colorectal carcinoma. J Hepatobiliary Pancreat Surg 1999; 6: 23-9.

36. Shimada $\mathrm{H}$, Tanaka K, Masui $\mathrm{H}$, et al. Results of surgical treatment for multiple ( $>$ or $=5$ nodules) bi-lobar hepatic metastases from colorectal cancer. Langenbecks Arch Surg 2004; 389: 114-21.

37. Malik HZ, Prasad KR, Halazun KJ, et al. Preoperative prognostic score for predicting survival after hepatic resection for colorectal liver metastases. Ann Surg 2007; 246: 806-14.

38. Goldstein MJ, Mitchell EP. Carcino-embryonic antigen in the staging and follow-up of patients with colorectal cancer. Cancer Invest 2005; 23: 338-51.

39. Aldrighetti L, Castoldi R, Di Palo S, et al. Prognostic factors for long-term outcome of hepatic resection for colorectal liver metastases. Chir Ital 2005; 57: 555-70.

40. Cheng SH, Horng CF, Clarke JL, et al. Prognostic index score and clinical prediction model of local regional recurrence after mastectomy in breast cancer patients. Int J Radiat Oncol Biol Phys 2006; 64: 1401-9.

41. Thompson IM, Ankerst DP, Chi C, et al. Assessing prostate cancer risk: results from the Prostate Cancer Prevention Trial. J Natl Cancer Inst 2006; 98: 529-34.
42. Zorzi D, Laurent A, Pawlik TM, Lauwers GY, Vauthey JN, Abdalla EK. Chemotherapy-associated hepatotoxicity and surgery for colorectal liver metastases. Br J Surg 2007; 94: 274-86.

43. Karoui M, Penna C, Amin-Hashem M, et al. Influence of preoperative chemotherapy on the risk of major hepatectomy for colorectal liver metastases. Ann Surg 2006; 243: 1-7.

44. Behrns KE, Tsiotos GG, Desouza NF, Krishna MK, Ludwig J, Nagorney DM. Hepatic steatosis as a potential risk factor for major hepatic resection. J Gastrointest Surg 1998; 2: 292-8.

45. Azoulay D, Castaing D, Smail A, et al. Resection of nonresectable liver metastases from colorectal cancer after percutaneous portal vein embolization. Ann Surg 2000; 231: 480-6.

46. Fernandez FG, Ritter J, Goodwin JW, Linehan DC, Hawkins WG, Strasberg SM. Effect of steatohepatitis associated with irinotecan or oxaliplatin pretreatment on resectability of hepatic colorectal metastases. J Am Coll Surg 2005; 200: 845-53.

47. Bipat S, Van Leeuwen MS, Comans EF, et al. Colorectal liver metastases: CT, MR imaging, and PET for diagnosis-meta-analysis. Radiology 2005; 237: 123-31.

48. Konopke R, Kersting S, Bergert H, et al. Contrast-enhanced ultrasonography to detect liver metastases: a prospective trial to compare transcutaneous unenhanced and contrast-enhanced ultrasonography in patients undergoing laparotomy. Int J Colorectal Dis 2007; 22: 201-7.

\section{Supporting information}

The following supporting information for this article is available online:

Fig. S1. (A) Recurrence-free survival rates of 201 patients according to the time of diagnosis of the liver metastases (synchronous vs. metachronous). (B) Overall survival rates of 201 patients according to the time of diagnosis of the liver metastases (synchronous vs. metachronous).

Fig. S2. (A) Recurrence-free survival rates of 201 patients according to the time of diagnosis of the liver metastases in an interval of $<12$ months after primary resection vs. 12 months and more. (B) Overall survival rates of 201 patients according to the time of diagnosis of the liver metastases in an interval of $<12$ months after primary resection vs. 12 months and more.

This material is available as part of the online article from http://www.blackwell-synergy.com/doi/abs/10.1111/j.1478-3231. 2008.01845.x (this link will take you to the article abstract).

Please note: Wiley-Blackwell is not responsible for the content or functionality of any supporting information supplied by the authors. Any queries (other than missing material) should be directed to the corresponding author for the article. 